\title{
Pharmacological Activities of Grevillea robusta, a Medicinal Plant of Bangladesh
}

\author{
Md. Sharif Ullah', Md. Al Amin Sikder ${ }^{2}$, Tasnuva Sharmin ${ }^{2}$ and Mohammad A. Rashid ${ }^{2}$ \\ ${ }^{1}$ Department of Pharmacy, State University of Bangladesh, Dhaka-1205, Bangladesh \\ ${ }^{2}$ Department of Pharmaceutical Chemistry, Faculty of Pharmacy, University of Dhaka, Dhaka-1000, Bangladesh
}

Received: May 01, 2014; $\quad$ Accepted: May 26, 2014; $\quad$ Published (Web): July 23, 2014

\begin{abstract}
The objective of this study was to evaluate the crude methanol extract of leaf of Grevillea robusta as well as its hexane, carbon tetrachloride, chloroform and aqueous soluble partitionates for cytotoxic, thrombolytic, membrane stabilizing and antimicrobial activities. In the brine shrimp lethality bioassay, the crude methanolic extract of $G$. robusta leaf revealed the highest cytotoxic activity with LC50 values as $1.50 \pm 0.45 \mu \mathrm{g} / \mathrm{ml}$ as compared to $0.45 \mu \mathrm{g} / \mathrm{ml}$ for vincristine sulphate. Among the extractives of G. robusta, the carbon tetrachloride soluble fraction showed $69.95 \pm 0.11 \%$ clot lysis as compared to $70.77 \%$ clot lysis by standard streptokinase. At concentration of $1.0 \mathrm{mg} / \mathrm{ml}$, the chloroform soluble fraction inhibited $40.31 \pm 0.59 \%$ and $62.93 \pm 0.73 \%$ of haemolysis of RBC induced by heat and hypotonic solution as compared to $42.12 \%$ and $71.90 \%$ by acetyl salicylic acid, respectively. The test samples also showed antimicrobial activity with zone of inhibition ranging from 7.0 to $17.0 \mathrm{~mm}$ in diameter. The chloroform soluble partitionate demonstrated the highest zone of inhibition $(17.0 \mathrm{~mm})$ against Salmonella Typhi.
\end{abstract}

Key words: Grevillea robusta, brine shrimp lethality, thrombolytic activity, membrane stabilizing activity, hypotonic solution, zone of inhibition.

\section{Introduction}

Grevillea robusta A. Cunn. ex R.Br. (Synonyms: Grevillea venusta A. Cunn. ex Meisn., Stylurus robustus A. Cunn. O. Deg.; Bengali name: rupasi), commonly known as the southern silky oak or Australian silver oak, is a fast growing evergreen tree belonging to the Proteaceae family. It is a native species of eastern coastal Australia and in other riverine, subtropical and rainforest environments that receive more than $1,000 \mathrm{~mm}$ per year of average rainfall. The flowers and fruits of the plant contain toxic hydrogen cyanide (Everist, 1974). Tridecylresorcinol of G. robusta is responsible for contact dermatitis (Menz et al., 2006). Previous phytochemical investigation provided six new 5-alkyl resorcinols (gravicycle, dehydrogravicycle, bisgravillol, dehydrobisgravillol, dehydrograviphane and methyldehydrograviphane) and eight known compounds (Chuang and $\mathrm{Wu}, 2007)$. Leaves contain rutin (Philippine Medicinal plants).

As part of our ongoing investigations on medicinal plants of Bangladesh (Kaisar et al., 2011 and Sharmin et al., 2012 and 2013), the crude methanol extract of leaf of $G$. robusta growing in Bangladesh as well as its organic and aqueous soluble fractions were studied for cytotoxic, thrombolytic, membrane stabilizing and antimicrobial activities for the first time and we, here in, report the results of our preliminary investigations.

\section{Materials and Methods}

Collection of plant materials and extraction: The leaf of G. robusta was collected from National Botanical Garden of Bangladesh in June, 2012. A voucher specimen (DACB-38206) for this plant has been deposited in Bangladesh National Herbarium, Dhaka, Bangladesh for future reference.

The sun dried and powdered leaves $(500 \mathrm{~g})$ were macerated in $1.5 \mathrm{~L}$ of methanol for 7 days. The extract was filtered through a fresh cotton bed and finally with Whatman filter paper number 1. It was concentrated with a rotary evaporator at reduced temperature and pressure. An aliquot $(5 \mathrm{~g})$ of the concentrated methanol extract was fractionated by the modified Kupchan (VanWagenen et al., 1993) partitioning protocol and the resultant partitionates were evaporated to dryness with a rotary evaporator to yield hexane (HXSF, $1.5 \mathrm{~g}$ ), carbon tetrachloride (CTCSF, $1.5 \mathrm{~g}$ ), chloroform (CSF, $1 \mathrm{~g}$ ) and

*Correspondence to: Mohammad A. Rashid; Tel.: +880-2-9661900, Extn. - 8137; Fax: +880-2-9667222; E-mail: rashidma@du.ac.bd 
aqueous (AQSF, $0.5 \mathrm{~g}$ ) soluble materials. The residues were then stored in a refrigerator until further use.

Brine shrimp lethality bioassay: This technique was applied for the determination of general toxic properties of the dimethylsulfoxide (DMSO) solutions of plant extractives against Artemia salina in a single day in vivo assay (Meyer et al., 1982). Vincristine sulphate was used as positive control.

Thrombolytic activity: The thombolytic activity was evaluated by the method developed by Prasad et al. (2006) by using streptokinase (SK) as positive control.

Membrane stabilizing activity: The membrane stabilizing activity of the extractives was assessed by evaluating their ability to inhibit heat- and hypotonic solution- induced hemolysis of human erythrocytes following the method developed by Omale et al. (2008).

Antimicrobial screening: Antimicrobial activity was determined by disc diffusion method (Bauer et al., 1966).

Statistical analysis: For all bioassays, sample data were compared with that of negative control by student's t-test

\section{Results and Discussion}

The present study was undertaken to evaluate the cytotoxic, thrombolytic, membrane stabilizing and antimicrobial activities of different organic and aqueous soluble materials of the crude methanol extract of $G$. robusta.

In brine shrimp lethality bioassay, all fractions demonstrated cytotoxic potential against $A$. salina with
$\mathrm{LC}_{50}$ values ranging from 1.50 to $191.14 \mu \mathrm{g} / \mathrm{ml}$. The crude methanol extract and the carbon tetrachloride soluble fraction revealed the presence of significant bioactive principles with $\mathrm{LC}_{50}$ values $1.50 \pm 0.45 \mu \mathrm{g} / \mathrm{ml}$ and $3.85 \pm$ $0.22 \mu \mathrm{g} / \mathrm{ml}$, respectively as compared to $0.45 \mu \mathrm{g} / \mathrm{ml}$ for Vincristine sulphate (Table 1).

The extractives of $G$. robusta demonstrated mild to moderate thrombolytic activity. The carbon tetrachloride and aqueous soluble fractions displayed $69.95 \pm 0.11 \%$ and $67.50 \pm 0.49 \%$ clot lysis, respectively as compared to $70.77 \%$ clot lysis revealed by standard streptokinase (Table 1).

At concentration $1.0 \mathrm{mg} / \mathrm{ml}$, the extractives of $G$. robusta protected the hemolysis of $\mathrm{RBCs}$ induced by heat and hypotonic solution as compared to the standard acetyl salicylic acid $(0.10 \mathrm{mg} / \mathrm{ml})$. The chloroform soluble fraction inhibited $40.31 \pm 0.59 \%$ and $62.93 \pm 0.73 \%$ of hemolysis of RBCs induced by heat and hypotonic solution as compared to $42.12 \%$ and $71.90 \%$ by acetyl salicylic acid, respectively (Table 1).

The antimicrobial activity of G. robusta test samples was evaluated against five gram positive and eight gram negative bacteria and three fungi and the results were compared with a broad spectrum antimicrobial agent, ciprofloxacin. Among the test samples of G. robusta, only the carbon tetrachloride and chloroform soluble fractions demonstrated antimicrobial activity with zone of inhibition ranging from 7.0 to $17.0 \mathrm{~mm}$. The highest zone of inhibition $(17.0 \mathrm{~mm})$ was displayed by the chloroform soluble fraction against Salmonella Typhi (Table 2).

Table 1. Cytotoxic, thrombolytic and membrane stabilizing activities of G. robusta.

\begin{tabular}{lcccc}
\hline Samples/ standard & $\begin{array}{c}\text { Brine shrimp lethality } \\
\text { bioassay LC }\end{array}$ \% $(\mu \mathrm{g} / \mathrm{ml})$ & & \multicolumn{2}{c}{ \% Inhibition of hemolysis } \\
\hline ME & $1.50 \pm 0.45$ & $64.94 \pm 0.56$ & $39.39 \pm 0.60$ & Hypotonic solution-induced \\
HXSF & $7.84 \pm 0.74$ & $29.76 \pm 0.34$ & $37.59 \pm 0.17$ & $37.56 \pm 0.42$ \\
CTCSF & $3.85 \pm 0.22$ & $69.95 \pm 0.11$ & $35.55 \pm 0.14$ & $26.91 \pm 0.82$ \\
CSF & $10.87 \pm 0.70$ & $47.67 \pm 0.63$ & $40.31 \pm 0.59$ & $11.89 \pm 0.44$ \\
AQSF & $191.14 \pm 0.19$ & $67.50 \pm 0.49$ & $10.82 \pm 0.05$ & $62.93 \pm 0.73$ \\
VS & $0.45 \pm 0.04$ & - & - & $17.89 \pm 0.52$ \\
Water & - & $3.791 \pm 0.55$ & - & - \\
SK & - & $70.77 \pm 0.36$ & - & - \\
ASA & - & - & $42.12 \pm 0.38$ & - \\
Hypotonic medium & - & - & - & - \\
\hline
\end{tabular}

$\mathrm{ME}=$ Methanolic crude extract $\mathrm{HXSF}=$ Hexane soluble fraction; $\mathrm{CTCSF}=$ Carbon tetrachloride soluble fraction; $\mathrm{CSF}=\mathrm{Chloroform}$ soluble fraction; $\mathrm{AQSF}=$ Aqueous soluble fraction; VS = Vincristine sulfate; $\mathrm{SK}=$ Streptokinase; ASA = Acetyl salicylic acid. 
Table 2. Antimicrobial activity of carbon tetrachloride and chloroform soluble materials of G. robusta.

\begin{tabular}{lccc}
\hline Test microorganisms & \multicolumn{1}{c}{ Diameter of zone of inhibition $(\mathrm{mm})$} & Ciprofloxacin \\
\cline { 2 - 4 } & CTCSF & CSF & $45.0 \pm 2.01$ \\
\hline Bacillus cereus & $9.0 \pm 0.93$ & $10.0 \pm 0.22$ & $42.0 \pm 1.17$ \\
B. megaterium & $8.0 \pm 1.12$ & $9.0 \pm 0.61$ & $42.0 \pm 0.73$ \\
B. subtilis & $8.0 \pm 0.83$ & $15.0 \pm 0.26$ & $42.0 \pm 0.23$ \\
Staphylococcus aureus & $9.0 \pm 1.05$ & $12.0 \pm 0.64$ & $42.0 \pm 0.56$ \\
Sarcina lutea & $9.0 \pm 0.31$ & $13.0 \pm 0.57$ & $42.0 \pm 0.43$ \\
Escherichia coli & $7.0 \pm 0.66$ & $13.0 \pm 0.65$ & $42.0 \pm 1.11$ \\
Pseudomonas aeruginosa & $10.0 \pm 0.39$ & $9.0 \pm 0.33$ & $45.0 \pm 0.73$ \\
Salmonella Typhi & $11.0 \pm 0.58$ & $17.0 \pm 0.42$ & $47.0 \pm 2.33$ \\
S. Paratyphi & $8.0 \pm 0.71$ & $9.0 \pm 0.58$ & $34.0 \pm 0.58$ \\
Shigella boydii & $7.0 \pm 0.56$ & $11.0 \pm 0.44$ & $42.0 \pm 0.22$ \\
Sh. dysenteriae & $7.0 \pm 0.47$ & $11.0 \pm 0.68$ & $40.0 \pm 0.45$ \\
Vibrio mimicus & $9.0 \pm 0.22$ & $10.0 \pm 0.31$ & $35.0 \pm 0.44$ \\
V. parahaemolyticus & $8.0 \pm 0.32$ & $10.0 \pm 0.06$ & $38.0 \pm 0.49$ \\
Sacharomyces cerevisiae & $8.0 \pm 0.17$ & $10.0 \pm 0.83$ & $37.0 \pm 0.33$ \\
Candida albicans & $7.0 \pm 0.47$ & $8.0 \pm 0.90$ & $38.0 \pm 0.11$ \\
Aspergillus niger & $9.0 \pm 0.66$ & $12.0 \pm 0.24$ & \\
\hline
\end{tabular}

$\mathrm{CTCSF}=$ Carbon tetrachloride soluble fraction; $\mathrm{CSF}=$ Chloroform soluble fraction

\section{Conclusion}

It is clearly evident from the above findings that $G$. robusta possesses significant cytotoxic, thrombolytic and membrane stabilizing activities. The plant is a good candidate for further systematic, chemical and biological studies to isolate the active principles.

\section{Acknowledgement}

The authors wish to thank Bangladesh National Herbarium for the identification of the plant species

\section{References}

Bauer, A.W., Kirby, W.M.M., Sheriss, J.C. and Turck, M. 1966. Antibiotic susceptibility testing by standardised single method. Am. J. Clin. Pathol. 45, 493-496.

Chuang, T.H. and Wu, P.L. 2007. Cytotoxic 5-alkylresorcinol metabolites from the leaves of Grevillea robusta. J. Nat. Prod. 70, 319-23.

Everist, S.L. 1974. Poisonous Plants of Australia, Angus \& Robertson.

Kaisar, M.A., Rahman, M.S., Rahman, M.Z., Hasan, C.M. and Rashid, M.A. 2011. A review on phytochemicals from some medicinal plants of Bangladesh. J. Pharm. Nutri. Sci. 1, 8795.

Menz, J., Rossi, R., Taylor, W.C. and Wall, L. 2006. Contact dermatitis from Grevillea 'Robyn Gordon'. Contact Dermatitis 15, 126-131.
Meyer, B.N., Ferringni, N.R., Puam, J.E., Lacobsen, L.B., Nichols, D.E. and McLaughlin, J.L. 1982. Brine shrimp: a convenient general bioassay for active constituents. Planta Med. 45, 31-32.

Omale, J. and Okafor, P.N. 2008. Comparative antioxidant capacity, membrane stabilization, polyphenols composition and cytotoxicity of the leaf and stem of Cissus multistriata. Afr. J. Biotechnol. 7, 3129-3133.

Philippine Medicinal Plants, [online], available: http://www. stuartxchange.com/Grevillea.html [Accessed: 3 May 2013]

Prasad, S., Kashyap, R.S., Deopujari, J.Y., Purohit, H.J., Taori, G.M. and Daginawala, H.F. 2007. Effect of Fagonia arabica (Dhamasa) on in vitro thrombolysis. BMC Complement. Alternat. Med. 7, 36 doi: 10.1186/1472-68827-36.

Sharmin, T., Islam, F., Kaisar, M.A., Uddin, M.G. and Rashid, M.A. 2012. Antioxidant, thrombolytic and cytotoxic activities of Picrasma javanica. Dhaka Univ. J. Pharm. Sci. 11, 71-74.

Sharmin, T., Sarker, P.K., Islam, F., Chowdhury, S.R., Quadery, T.M., Mian, M.Y., Rahman, S.M.A, Chowdhury, Z.S. and Ullah, M.S. 2013. Investigation of biological activities of Allamanda blanchetii, the violet Allamanda. J. Pharm. Res. 6, 761-764.

Van-Wagenen, B.C., Larsen, R., Cardellina, J.H., Randazzo, D., Lidert, Z.C. and Swithenbank, C. 1993. Ulosantoin, a potent insecticide from the sponge Ulosa ruetzleri. J. Org. Chem. 58, 335-337. 